\title{
Temperature-Dependent Rate Constants and Substituent Effects for the Reactions of Hydroxyl Radicals with Three Partially Fluorinated Ethers

\author{
K.-J. Hsu ${ }^{\dagger}$ and W. B. DeMore* \\ Jet Propulsion Laboraton, Califormia Institute of Technology, Pasadena, California 91109 \\ Darsivad. Fohrumn 28 1995; In Final Form: May 10, $1995^{\circ}$
} \\ NASA-CR-203156

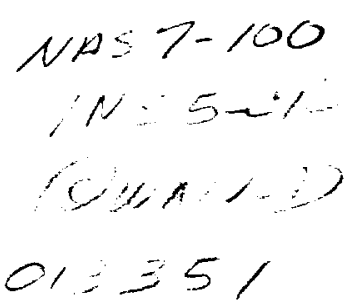

Rate constants and temperature dependencies for the reactions of $\mathrm{OH}$ with $\mathrm{CF}_{3} \mathrm{OCH}_{3}$ (HFOC-143a), $\mathrm{CF}_{2} \mathrm{HOCF}_{2} \mathrm{H}$ (HFOC-134), and $\mathrm{CF}_{3} \mathrm{OCF}_{2} \mathrm{H}$ (HFOC-125) were studied using a relative rate technique in the temperature range $298-393 \mathrm{~K}$. The following absolute rate constants were derived: HFOC-143a, $1.9 \mathrm{E}-12$ $\exp (-1555 / T)$; HFOC-134, 1.9E-12 exp(-2006/T); HFOC-125, 4.7E-13 exp(-2095/T). Units are $\mathrm{cm}^{3}$ molecule ${ }^{-1} \mathrm{~s}^{-1}$. Substituent effects on $\mathrm{OH}$ abstraction rate constants are discussed, and it is shown that the $\mathrm{CF}_{3} \mathrm{O}$ group has an effect on the $\mathrm{OH}$ rate constants similar to that of a fluorine atom. The effects are related to changes in the $\mathrm{C}-\mathrm{H}$ bond energies of the reactants (and thereby the activation energies) rather than changes in the preexponential factors. On the basis of a correlation of rate constants with bond energies, the respective $D(\mathrm{C}-\mathrm{H})$ bond strengths in the three ethers are found to be 102,104 , and $106 \mathrm{kcal} / \mathrm{mol}$, with an uncertainty of about $1 \mathrm{kcal} / \mathrm{mol}$.

\section{Introduction}

Partially fluorinated ethers are of some interest as possible replacements for chlorofluorocarbons (CFCs), since they have zero ozone depletion potential and can be removed from the atmosphere by $\mathrm{OH}$ attack, thus reducing their global warming potential. To estimate the atmospheric lifetimes of such species, accurate data for the rate constants and their temperature dependencies are needed. The rate constants for these compounds also give further information concerning substituent effects on the rates of $\mathrm{OH}$ abstraction reactions. Relatively few experimental data are available for $\mathrm{OH}$ reaction rates with this class of compounds. The only published measurements are those of Zhang et al.,' Garland et al., ${ }^{2}$ and Orkin et al. ${ }^{3}$ Some of these measurements are in substantial disagreement, possibly due to the effect of impurities. All of the published data are based on observations of the rate of $\mathrm{OH}$ loss in the presence of the compound, a method which has the advantage of producing absolute rate constants but the disadvantage of being susceptible to spurious $\mathrm{OH}$ loss due to impurities or secondary products.

In the present work we have employed a relative rate technique which is insensitive to reactions of impurities as well as secondary products and has been shown to yield accurate relative rate constants for several halogenated alkanes. ${ }^{4-8}$ When combined with absolute rate constants for reference compounds such as $\mathrm{CH}_{4}, \mathrm{CH}_{3} \mathrm{CCl}_{3}$, and $\mathrm{CF}_{3} \mathrm{CF}_{2} \mathrm{H}$, absolute rate constants can be determined.

\section{Experimental Section}

The relative rate technique used in this work has been described in several recent publications. ${ }^{4-8}$ The method involves measurement of the fractional loss of the reactant compound compared to a reference compound, in the presence of $\mathrm{OH}$. The $\mathrm{OH}$ radicals are produced by $254 \mathrm{~nm}$ photolysis of $\mathrm{O}_{3}\left((5-10) \times 10^{16} \mathrm{~cm}^{-3}\right)$ in the presence of water vapor $\left((3-5) \times 10^{17} \mathrm{~cm}^{-3}\right)$ or by direct photolysis of $\mathrm{H}_{2} \mathrm{O}$ at $185 \mathrm{~nm}$. The experiments are done in a temperature-controlled quartz cell. operated in either a slow-flow or stopped-flow mode. The

\footnotetext{
Present address: Department of Atmospheric Sciences. National Taiwan University. Taipei, Tajwan.

\& Abstract published in Advance ACS Abstracts. June 15. 1995.
}

TABLE 1: Rate Constants of the Reference Compounds Used in This Work

\begin{tabular}{lll}
\hline \multicolumn{1}{c}{ ref compound } & Arrhenius rate constant ${ }^{u}$ & $k(298 \mathrm{~K})$ \\
\hline $\mathrm{CH}_{3} \mathrm{CF}_{2} \mathrm{H}(152 \mathrm{a})^{b}$ & $2.3 \mathrm{E}-12 \exp (-1275 / T)$ & $3.2 \mathrm{E}-14$ \\
$\mathrm{CH}_{2} \mathrm{~F}_{2}{ }^{b}$ & $1.8 \mathrm{E}-12 \exp (-1552 / T)$ & $9.8 \mathrm{E}-15$ \\
$\mathrm{CH}_{3} \mathrm{CCl}_{3}{ }^{c}$ & $1.8 \mathrm{E}-12 \exp (-1550 / T)$ & $9.9 \mathrm{E}-15$ \\
$\mathrm{CF}_{3} \mathrm{H}^{b}$ & $6.4 \mathrm{E}-13 \exp (-2354 / T)$ & $2.4 \mathrm{E}-16$ \\
$\mathrm{CH}_{4}{ }^{c}$ & $2.65 \mathrm{E}-12 \exp (-1800 / T)$ & $6.3 \mathrm{E}-15$ \\
$\mathrm{CF}_{3} \mathrm{CF}_{2} \mathrm{H}(125)^{c}$ & $5.6 \mathrm{E}-13 \exp (-1700 / T)$ & $1.9 \mathrm{E}-15$
\end{tabular}

a Rate constants for $\mathrm{CH}_{4}, \mathrm{CH}_{3} \mathrm{CCl}_{3}$, and HFC-125 from JPL Publication 94-26; all others from Hsu and DeMore. ${ }^{8}$ A secondary reference standard. See Discussion. 'A primary reference standard. See Discussion.

$\mathrm{H}$ atoms produced in the $\mathrm{H}_{2} \mathrm{O}$ photolysis are converted to the relatively unreactive $\mathrm{HO}_{2}$ in the presence of $\mathrm{O}_{2}$. The cylindrical cell is $10 \mathrm{~cm}$ in length and $5 \mathrm{~cm}$ in diameter and is either waterjacketed (for the $\mathrm{O}_{3}$ photolysis experiments) or wrapped with heating tape and insulating material for the $\mathrm{H}_{2} \mathrm{O}$ photolysis experiments. Residence times in the cell for the slow-flow mode are about $1 \mathrm{~min}$. Concentrations are monitored with a Nicolet 20SX FTIR, operated at $0.5 \mathrm{~cm}^{-1}$ resolution in the absorbance mode using a White cell with a 3-m path length. Other details of the experimental procedure are described in the papers referenced above.

Several factors are involved in the choice of reference compounds: (1) the accuracy of the absolute rate constant; (2) the magnitude of the reference rate constant, which should be similar to that of the reactant in order to obtain measurable conversions of both compounds; (3) the IR spectral bands should be strong and well-defined and should not interfere with those of the reactant. In the present work we have used the reference compounds which are shown in Table 1.

\section{Results}

The rate constant ratio measurements at different temperatures are shown in Table 2. Linear least-squares fits to these data in Arrhenius form are listed in Table 3. Using the reference rate constant expressions from Table 1 , the ratio data from Table 2 were converted to rate constants, and the resulting data are plotted in Figures 1-3. The figures include data from other laboratories for comparison. 
11142 J. Phys. Chem., Vol. 99. No. 28, 1995

TABLE 2: Measured Rate Constant Ratios, $k / k_{\text {ref, }}$ as a Function of Temperature

\begin{tabular}{|c|c|c|c|c|c|c|c|c|c|c|c|}
\hline \multicolumn{4}{|c|}{$\mathrm{CF}_{3} \mathrm{OCH}_{3}$ (HFOC-143a) } & \multicolumn{2}{|c|}{$\mathrm{CF}_{2} \mathrm{HOCF}_{2} \mathrm{H}(\mathrm{HFOC}-134)$} & \multicolumn{6}{|c|}{$\mathrm{CF}_{3} \mathrm{OCF}_{2} \mathrm{H}(\mathrm{HFOC}-125)$} \\
\hline$T(\mathrm{~K})$ & $k / k_{\mathrm{ret}} \mathrm{t}^{\prime}$ & $T(\mathrm{~K})$ & $k / k_{\mathrm{ret}}^{b}$ & $T(\mathbf{K})$ & $k / k_{\text {ref }}{ }^{c}$ & $T(\mathrm{~K})$ & $k / k_{\text {ret }}{ }^{d}$ & $T(\mathrm{~K})$ & $k / k_{\text {ref }}$ & $T(\mathbf{K})$ & $k i k_{\mathrm{re}}$ \\
\hline 298 & 0.335 & 301 & 0.990 & 298 & 0.236 & 298 & 1.806 & 298 & 0.073 & 318 & 0.223 \\
\hline 318 & 0.370 & 321 & 1.005 & 298 & 0.232 & 317 & 1.658 & 313 & 0.080 & & \\
\hline 333 & 0.364 & 370 & 1.074 & 307 & 0.222 & 333 & 1.520 & 345 & 0.076 & & \\
\hline 348 & 0.385 & & & 315 & 0.248 & 360 & 1.542 & 377 & 0.069 & & \\
\hline 363 & 0.383 & & & 333 & 0.262 & 385 & 1.424 & & & & \\
\hline \multirow[t]{2}{*}{381} & 0.389 & & & 350 & 0.283 & 393 & 1.455 & & & & \\
\hline & & & & 368 & 0.311 & & & & & & \\
\hline
\end{tabular}

${ }^{\prime} \mathrm{HFC}-152 \mathrm{a},{ }^{b} \mathrm{CH}_{2} \mathrm{~F}_{2},{ }^{\circ} \mathrm{CH}_{3} \mathrm{CCl}_{3},{ }^{d} \mathrm{CF}_{3} \mathrm{H},{ }^{\circ} \mathrm{CH}_{4}$, and $/ \mathrm{HFC}-125$ were the reference compounds.

TABLE 3: Arrhenius Expressions for the Rate Constant Ratio Data

\begin{tabular}{cll}
\hline \multicolumn{1}{c}{ reactant } & \multicolumn{1}{c}{ reference } & \multicolumn{1}{c}{$k / k_{\text {ret }}$} \\
\hline $\mathrm{CF}_{3} \mathrm{OCH}_{3}$ (HFOC-143a) & $\mathrm{CH}_{3} \mathrm{CF}_{2} \mathrm{H}(152 \mathrm{a})$ & $(0.65 \pm 0.08) \exp (-190 \pm 43) / T$ \\
& $\mathrm{CH}_{2} \mathrm{~F}_{2}$ & $(1.55 \pm 0.10) \exp (-136 \pm 43) / T$ \\
$\mathrm{CF}_{2} \mathrm{HOCF}_{2} \mathrm{H}(\mathrm{HFOC}-134)$ & $\mathrm{CH}_{3} \mathrm{CCl}_{3}$ & $(1.05 \pm 0.20) \exp (-456 \pm 62) / T$ \\
$\mathrm{CF}_{3} \mathrm{OCF} \mathrm{H}_{2} \mathrm{H}(\mathrm{HFOC}-125)$ & $\mathrm{CF}_{3} \mathrm{H}$ & $(0.74 \pm 0.10) \exp (259 \pm 48) / T$ \\
& $\mathrm{CH}_{4}$ & $10.054 \pm 0.02) \exp (107 \pm 120) / T$
\end{tabular}

"Errors shown are standard deviations.

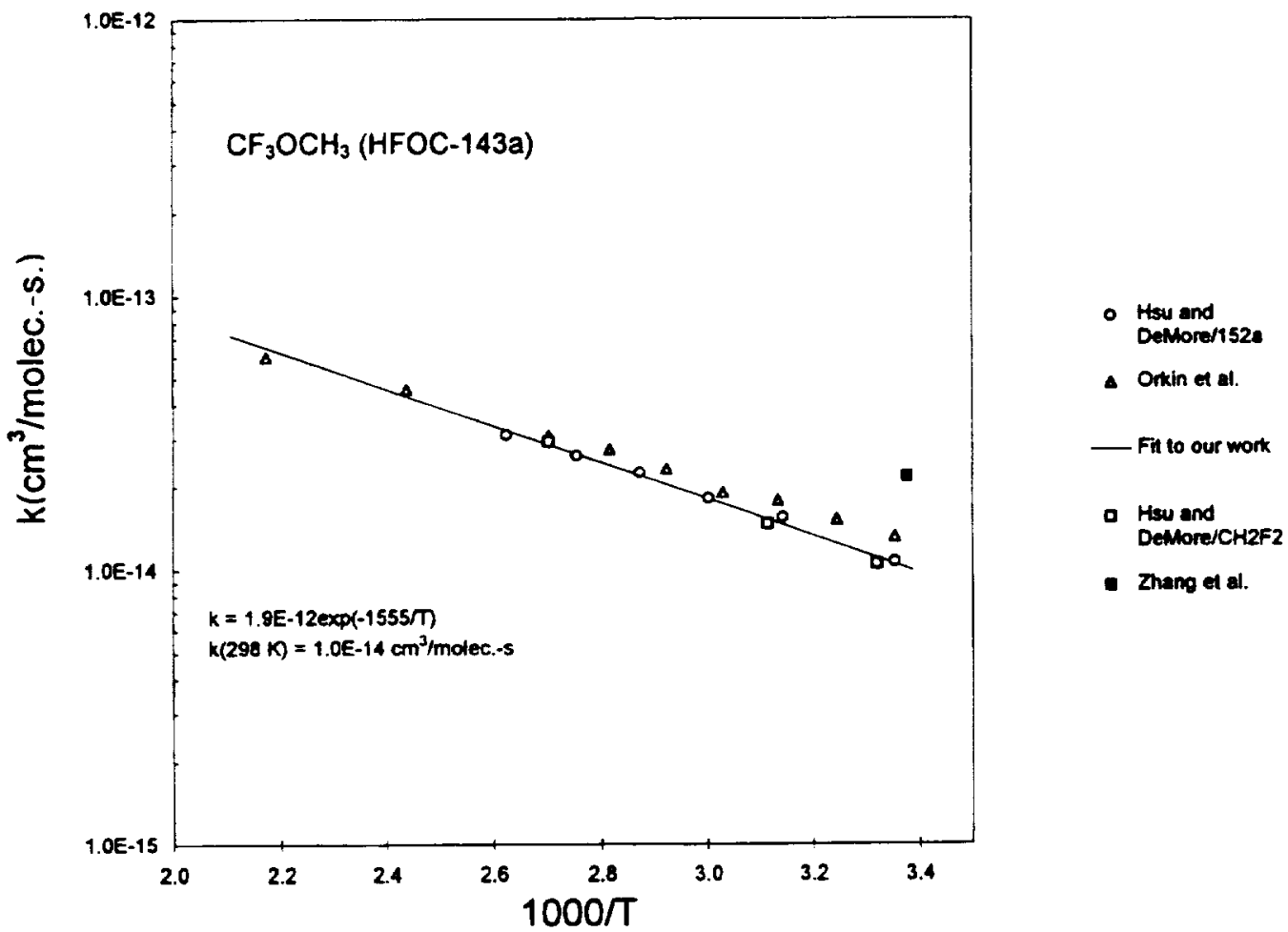

Figure 1. Arrhenius plot of data for $\mathrm{CF}_{3} \mathrm{OCH}_{3}$ (HFOC-143a).

HFOC-143a. Our data (Figure 1), based on the two reference gases HFC-152a and HFC-32, are in excellent agreement (about $2 \%$ or better). Normally only one reference gas would be used, but because of the somewhat anomalous behavior of the $\mathrm{CF}_{3} \mathrm{O}$ group in this compound when compared to HFOC-125 (see Discussion), two separate sets of data were taken. The agreement between them is an indication of experimental consistency, i.e., freedom from unsuspected error sources such as product interference with the IR spectra. (Such interference is, in any case, usually detectible from the IR results at different wavelengths.) Since the reference rate constant used for HFC. 32 is based on that of HFC- $152 \mathrm{a},{ }^{8}$ the agreement does not confirm absolute accuracy. That depends on the validity of our rate constant for HFC-152a, which was determined from those of both $\mathrm{CH}_{4}$ and $\mathrm{CH}_{3} \mathrm{CCl}_{3}$. The results from these two reference standards at $298 \mathrm{~K}$ for the $152 \mathrm{a}$ rate constant are in agreement to within $3 \%$. The values we used for $\mathrm{CH}_{4}$ and $\mathrm{CH}_{3} \mathrm{CCl}_{3}$ (the same as in Table 1) are well-established absolute rate constants which have been shown in our previous ratio experiments ${ }^{8}$ to be self-consistent to within better than $3 \%$. It is probable, but of course not certain, that they are accurate to within about $5 \%$ on an absolute basis. Taking $5 \%$ as the absolute accuracy of both the standard rate constants and considering that the two ratio measurements are each accurate to at least $3 \%$, the net uncertainty in $k(152 a)$ is calculated to be $3 \%$. (The combined error of a single measurement would be $6 \%$, but since there are two independent measurements the net uncertainty is half that.) For HFOC-143a, the two sets of ratio measurements (from HFC$152 \mathrm{a}$ and HFC-32) agree on average to within $2 \%$. Therefore, the ratio measurements add relatively little uncertainty, and the net uncertainty in $k$ for HFOC-143a (in this temperature range) is about $7 \%$. The uncertainty in the $E / R$ value is about \pm 200 




- Hsu and DeMore/CH3CCl3

- 93 Garland et al.

- Fil to our data

Figure 2. Arrhenius plot of data for $\mathrm{CF}_{2} \mathrm{HOCF} 2 \mathrm{H}$ (HFOC-134).

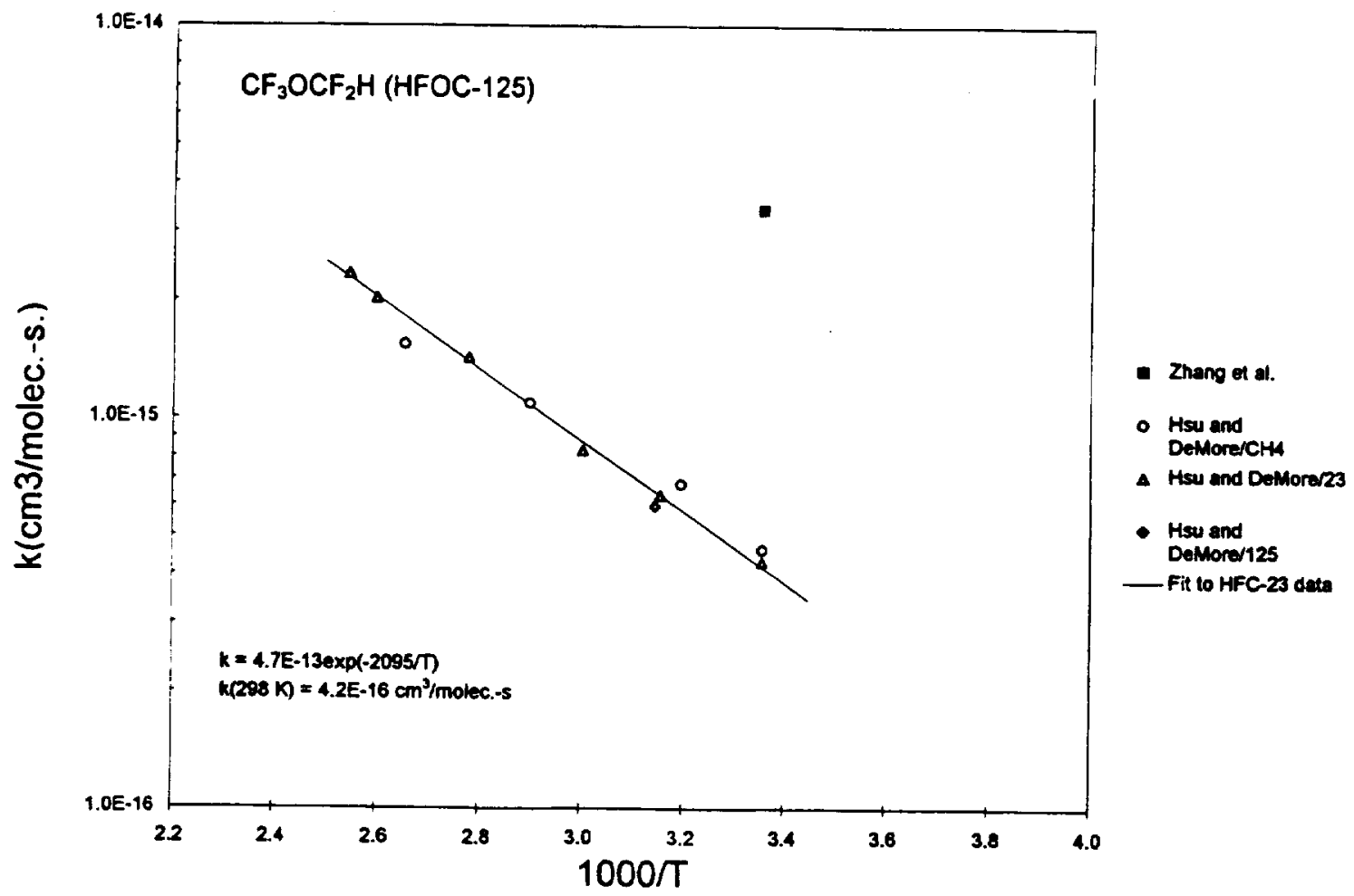

Figure 3. Arrhenius plot of data for $\mathrm{CF}_{3} \mathrm{OCF}_{2} \mathrm{H}$ (HFOC-125).

$K$, most of which arises from possible error in the $E / R$ value for HFC-152a, which we estimate to be about $\pm 150 \mathrm{~K}$.

HFOC-134 (Figure 2). Methyl chloroform was the reference gas in these experiments. Since that gas is one of our primary standards and the rate constant has been shown to be consistent within a very few percent with the other primary references. $\mathrm{CH}_{4}$ and HFC-125. the major uncertainty is from the ratio experiment itself, which is about $3-5 \%$. Conservative uncertainties in $k(298 \mathrm{~K})$ and $E / R$ are about $10 \%$ (since only one ratio was measured) and $\pm 200 \mathrm{~K}$. respectively.
HFOC-125 (Figure 3). The first experiments were with $\mathrm{CH}_{4}$ as the reference compound. These measurements were conducted to establish the magnitude of the HFOC-125 rate constant. It turned out to be slower than expected, and therefore $\mathrm{CH}_{4}$ was not an ideal reference gas because of the mismatch between the rate constants. Additional experiments were done with $\mathrm{CF}_{3} \mathrm{H}$ as the reference. A single point using HFC-125 was also taken, as a consistency check. The derived rate constant for HFOC-125 in Table 4 is based on the $\mathrm{CF}_{3} \mathrm{H}$ rate constant, which was determined with reference to HFC-125 in 
TABLE 4: Derived Rate Constants

\begin{tabular}{lll}
\hline \multicolumn{1}{c}{ compound } & Arrhenius rale constant & $k(298 \mathrm{~K})^{a}$ \\
\hline $\mathrm{CF}_{3} \mathrm{OCH}_{3}$ (HFOC-143a) & $1.9 \mathrm{E}-12 \exp (-1555 / \mathrm{T})^{b}$ & $1.0 \mathrm{E}-14$ \\
$\mathrm{CF}_{2} \mathrm{HOCF}_{2} \mathrm{H}(\mathrm{HFOC}-134)$ & $1.9 \mathrm{E}-12 \exp (-2006 / \mathrm{T})^{c}$ & $2.3 \mathrm{E}-15$ \\
$\mathrm{CF}_{3} \mathrm{OCF}_{2} \mathrm{H}$ (HFOC-125) & $4.7 \mathrm{E}-13 \exp (-2095 / \mathrm{T})^{\mathrm{H}}$ & $4.2 \mathrm{E}-16$
\end{tabular}

" Units are $\mathrm{cm}^{3} /($ molecule $\mathrm{s}){ }^{b}$ Fit to data from experiments with $\mathrm{CH}_{3} \mathrm{CF}_{2} \mathrm{H}$ and $\mathrm{CH}_{2} \mathrm{~F}_{2}$ as reference compounds. 'Methyl chloroform was the reference compound. ${ }^{4} \mathrm{Fit}$ to data from experiments with $\mathrm{CF}_{3} \mathrm{H}$ as reference compound.

our previous study. ${ }^{8}$ Since the ratio measurements introduce relatively little additional error, typically $5 \%$ or less, the accuracy of the $\mathrm{CF}_{3} \mathrm{H}$ rate constant is within about $5 \%$ of the accuracy of the HFC- 125 rate constant, which in tum is about $5 \%$. We expect that $k(298 \mathrm{~K})$ for HFOC- 125 from our derived Arrhenius expression is accurate to within $10 \%$. As in the other cases, the uncertainty in $E / R$ is about $\pm 200 \mathrm{~K}$, again with most of the uncertainty arising from that in E/R for HFC-125.

Table 4 summarizes the recommended rate constants from the present work. These are from a linear least-squares fit of all our derived rate constant data, except for the case of HFOC125 where we used only the data obtained with $\mathrm{CF}_{3} \mathrm{H}$ as the reference compound.

\section{Discussion}

Accuracy of the Method. Relative rate constants are by their nature intrinsically accurate, since they require only very simple ratio measurements and are not affected by factors such as the purity of the samples. As we discussed in the Results, the ratio measurements introduce only an additional 3-5\% uncertainty in $k$ at a given temperature, and in many cases even less. Relative Arrhenius $A$ factors can be determined to within a factor of about 1.3 , and relative $E / R$ values within $50-75 \mathrm{~K}$. The absolute accuracy of rate constants determined by this technique depends largely on the validity of the reference rate constants. We use $\mathrm{CH}_{4}, \mathrm{CH}_{3} \mathrm{CCl}_{3}$, and $\mathrm{CF}_{3} \mathrm{CF}_{2} \mathrm{H}$ as the primary standards, and in previous work ${ }^{4-8}$ we have shown that the rate constants of these three standards (determined from absolute measurements $)^{9}$ are mutually consistent to within a few percent. The simplest interpretation of this consistency is that the absolute rate constants for these three standards are accurate.

The use of secondary standards such as $\mathrm{CH}_{3} \mathrm{CF}_{2} \mathrm{H}$ (HFC152a) or $\mathrm{CF}_{3} \mathrm{H}$ (HFC-23), for which we have determined the rate constants relative to the primary standards, is sometimes convenient in order to match rate constants or to avoid IR spectral overlaps. This procedure might be assumed to lead to an accumulation of error which would not be detected. That this is not the case can be seen by considering the self-checking nature of the measurements, as in the example of HFOC-143a. There we compared HFOC-143a with both HFC-152a and HFC32 and have previously intercompared the latter two compounds. ${ }^{8}$ Thus there is a closed relationship among the three ratios between the three compounds. The good agreement between rate constants obtained for HFOC-143a from the two secondary standards (about $2 \%$ on average) shows that no significant error has accumulated in the sequence from HFC152a to HFC-32 to HFOC-143a. The rate constant for HFC$152 \mathrm{a}$ was in turn referenced to both $\mathrm{CH}_{4}$ and $\mathrm{CH}_{3} \mathrm{CCl}_{3}$, with excellent agreement. ${ }^{8}$ Both $\mathrm{CH}_{4}$ and $\mathrm{CH}_{3} \mathrm{CCl}_{3}$ have been compared to other compounds, such as $\mathrm{CF}_{3} \mathrm{CH}_{2} \mathrm{~F}$ (HFC-134a) and $\mathrm{CFCl}_{2} \mathrm{CH}_{3}$ (HCFC-141b), with better than $1 \%$ agreement among all three ratio measurements. The ratios so obtained agree within $2 \%$ with the ratio of recommended absolute measurements. ${ }^{9}$ HFC-152a has also been compared with many other compounds. Thus the interlocking and self-testing nature of the ratio measurements precludes the accumulation of undetected errors beyond the level of a few percent.

Comparisons with Previous Work. Our data for HFOC143a (Figure 1) are in good agreement (factor of 1.3 at room temperature) with the earlier measurements of Orkin et al. ${ }^{3}$ who report $k=1.13 \mathrm{E}-12 \exp (-1330 / T)$. Both sets of data are about a factor of 2 lower than the single point of Zhang et al.' As with their HFOC-125 data mentioned below, the Zhang et al. measurement may have been affected by impurities in the sample.

For HFOC-134 (Figure 2), the only previous data are those of Garland et al..$^{2}$ Our rate constants are lower and correspond to significantly different Arrhenius parameters. The rate constant reported by Garland et al. was $k=5.4 \mathrm{E}-13 \exp (-$ $1560 / T) \mathrm{cm}^{3} /$ molecule s. As shown in our previous work, ${ }^{8}$ compounds with two equivalent hydrogen atoms, such as HFOC-134, normally have an $A$ factor for $\mathrm{OH}$ abstraction which is at least twice that value. $A$ factors which fall significantly below the expected value are frequently indicative of impurity effects, particularly at low temperatures where the contributions to the rate of $\mathrm{OH}$ loss become increasingly important.

For HFOC-125 (Figure 3), there are no previous data except that of Zhang et al. ${ }^{1}$ The much higher point reported by Zhang et al. is probably also due to impurity effects.

Substituent Effects on the Rate Constants. To examine substituent effects systematically, it is useful to consider the compounds as substituted methanes and to normalize the rate constants to a per hydrogen basis. For example, the compound $\mathrm{CH}_{3} \mathrm{CH}_{3}$ is viewed as methylmethane, with $\mathrm{CH}_{3}$ being the substituent group. There are six equivalent reactive sites. Compounds such as $\mathrm{CH}_{3} \mathrm{CF}_{2} \mathrm{H}$ (HFC-152a) have two distinct reactive sites. The total reaction rate is the sum of two separate reactions, one on the $\mathrm{CH}_{3}$ group and one on the $\mathrm{CF}_{2} \mathrm{H}$ group.

Substituents affect rate constants in two ways. The most important is the effect on the $\mathrm{C}-\mathrm{H}$ bond energy, which in turn alters the activation energy of the reaction. A second and less important effect is on the preexponential factor. In our previous work. ${ }^{8}$ we have shown that ratios of Arrhenius $A$ factors are remarkably proportional to the number of (equivalent) $\mathrm{H}$ atoms in the molecule, regardless of the nature of the substituents. Deviations from proportionality to the number of $\mathrm{H}$ atoms are usually less than a factor of 1.3. As discussed in later paragraphs, the present data are consistent with this generalization.

Substituent effects on $\mathrm{OH}$ reactions are of interest in connection with the development of empirical methods for the estimation of rate constants. Effects of several substituents, both single and multiple, are illustrated in Figure 4, which is a graph of $\log (k(298 \mathrm{~K}) / n(\mathrm{H}))$ for reactants in which all the $\mathrm{C}-\mathrm{H}$ bonds are identical, with $n(\mathrm{H})$ being the number of $\mathrm{H}$ atoms. In $\mathrm{CH}_{3} \mathrm{CCl}_{3}$, for example, the relevant group is $\mathrm{CCl}_{3}$. From this graph the relative effects of different groups and combinations of groups can be readily seen. The rate constants are considered on a per hydrogen basis, as discussed above. The point of reference in Figure 4 is $\mathrm{CH}_{4}$, since all the compounds are considered as substituted methanes.

As seen in Figure 4, most groups enhance the $\mathrm{C}-\mathrm{H}$ reactivity compared to $\mathrm{CH}_{4}$. This is also the case for the $\mathrm{CF}_{3} \mathrm{O}$ group, since $\mathrm{CF}_{3} \mathrm{OCH}_{3}$ has a higher reactivity per $\mathrm{C}-\mathrm{H}$ bond than $\mathrm{CH}_{4}$. The only known (single) groups which reduce $k / n(\mathrm{H})$ are $\mathrm{CF}_{3}$ and $\mathrm{CF}_{2} \mathrm{Cl}$ (as in HFC-143a and HCFC-142b; see Figure 4). The $\mathrm{CFCl}_{2}$ group (in $\mathrm{CFCl}_{2} \mathrm{CH}_{3}, \mathrm{HCFC}-141 \mathrm{~b}$ ) has a slight enhancing effect, in keeping with the trend toward the fully chlorinated group $\mathrm{CCl}_{3}$, which has a definite enhancing effect (as in $\mathrm{CH}_{3} \mathrm{CCl}_{3}$ ). Qualitatively, these and other effects discussed 


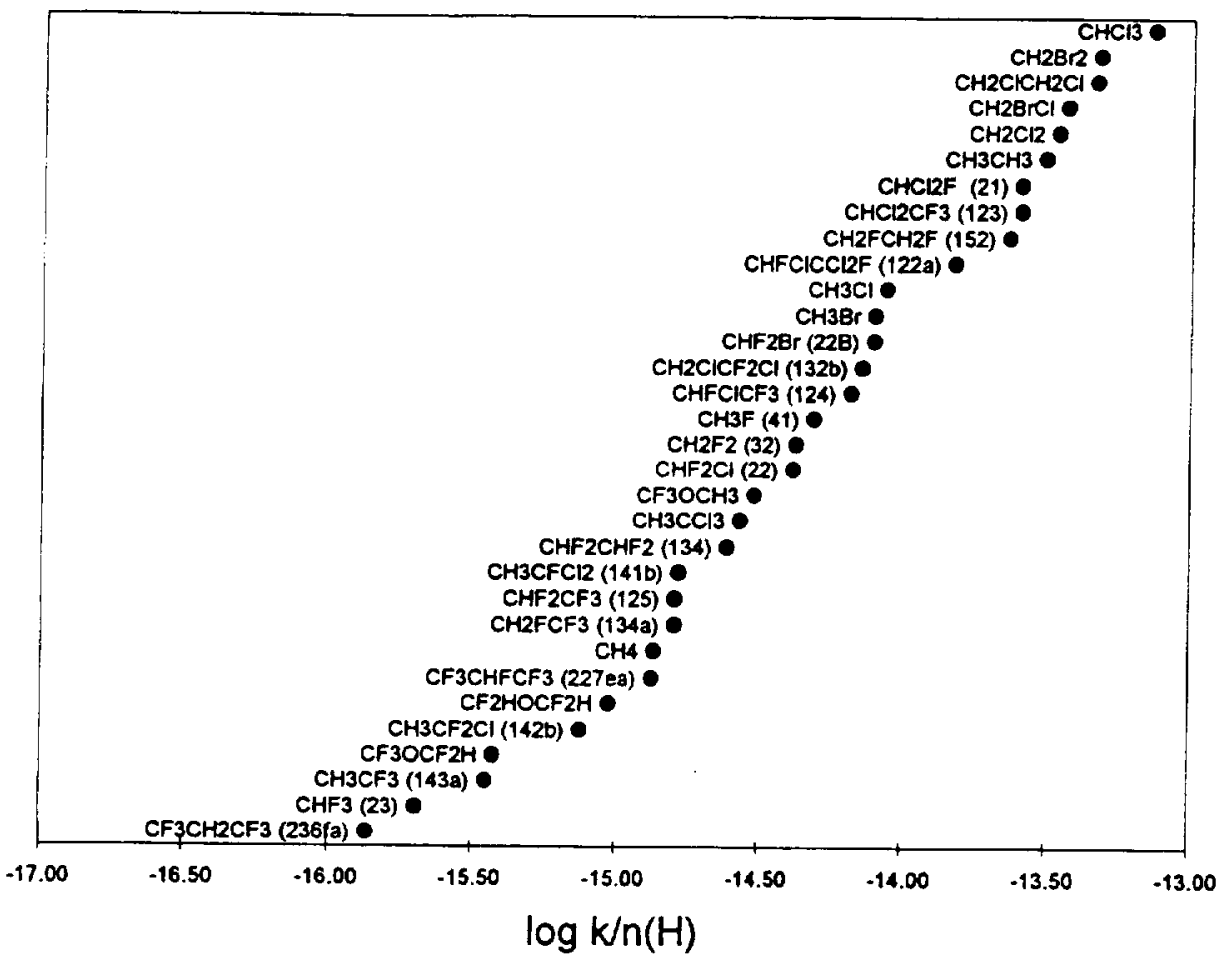

Figure 4. Graphical representation of the $298 \mathrm{~K}$ rate constants for the $\mathrm{OH}$ reactions with several compounds. normalized to a per hydrogen basis. Rate constants are from refs $4-8$ or from JPL 94-26.

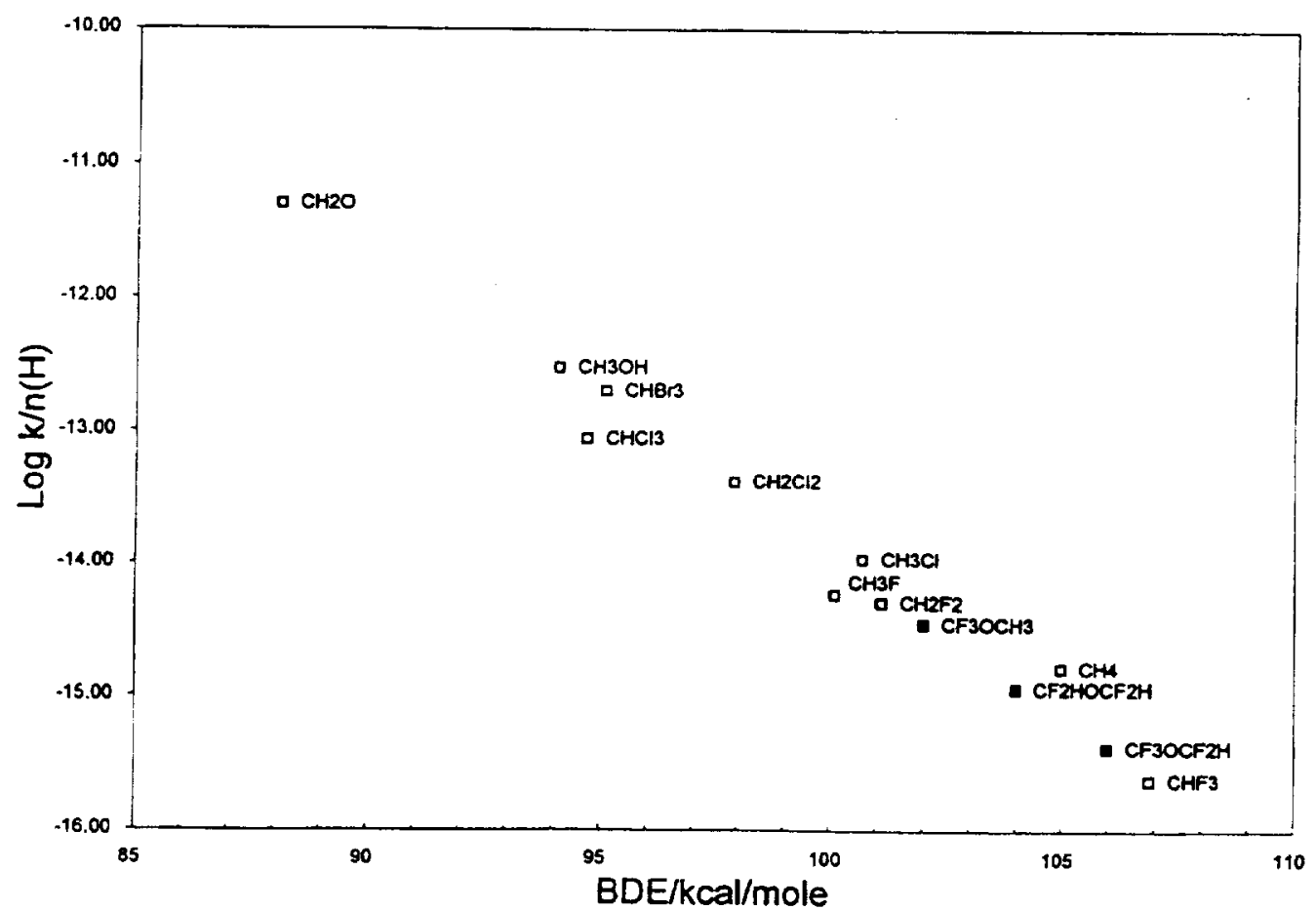

Figure 5. Correlation of $\log (k(298 \mathrm{~K}) / n(\mathrm{H}))$ with $\mathrm{C}-\mathrm{H}$ bond energies for several methane derivatives, used to derive the $\mathrm{C}-\mathrm{H}$ bond energies in the fluoro ethers. Open squares are data using rate constants from refs 4-8 or JPL 94-26. and enthalpies as listed in JPL 94-26. Solid squares are the fits for the respective ethers.

below can be correlated with the density of valence electrons in the group.

It is known (and is evident in Figure 4) that the presence of multiple substituent groups on a carbon atom affects the $\mathrm{C}-\mathrm{H}$ reactivity by an amount that is less than the effects of the substituents considered individually. For example, a second $\mathrm{Cl}$ atom (as in $\mathrm{CH}_{2} \mathrm{Cl}_{2}$ ) has a smaller effect on the rate constant than does the first (as in $\mathrm{CH}_{3} \mathrm{Cl}$ ), and a third has still less effect (as in $\mathrm{CHCl}_{3}$ ). The respective increments in $\log (k(298 \mathrm{~K}) / n(\mathrm{H}))$ for the series $\mathrm{CH}_{4}$ to $\mathrm{CH}_{3} \mathrm{Cl}, \mathrm{CH}_{3} \mathrm{Cl}$ to $\mathrm{CH}_{2} \mathrm{Cl}_{2}$, and $\mathrm{CH}_{2} \mathrm{Cl}_{2}$ to $\mathrm{CHCl}_{3}$ are $0.80,0.66$, and 0.27 . This lack of strict additivity poses a problem for rate constant estimation methods, which must account for it empirically.

The fluorine atom is a unique case with regard to the effect of multiple substitution by halogen atoms. The first $F$ atom enhances the rate constant per $\mathrm{H}$ atom, the second one decreases it slightly, and the third one causes a very pronounced decrease. The rate constant for $\mathrm{CHF}_{3}$ is thus among the slowest of those 
TABLE 5: Comparison of Arrhenius Parameters for HFOCs and HFCs

\begin{tabular}{|c|c|c|c|}
\hline compound & $\begin{array}{c}A \text { factors } \\
\left(\mathrm{cm}^{3 /}\right. \\
\text { (molecule s)) }\end{array}$ & $\begin{array}{l}E / R \\
(\mathrm{~K})\end{array}$ & ref \\
\hline $\begin{array}{l}\mathrm{CF}_{3} \mathrm{OCH}_{3}(\mathrm{HFOC}-143 \mathrm{a}) \\
\mathrm{CF}_{3} \mathrm{CH}_{3}(\mathrm{HFC}-143 \mathrm{a}) \\
\mathrm{CH}_{3} \mathrm{~F}(\mathrm{HFC}-41)\end{array}$ & $\begin{array}{l}1.9 \mathrm{E}-12 \\
1.3 \mathrm{E}-12 \\
2.2 \mathrm{E}-12\end{array}$ & $\begin{array}{l}1555 \\
2043 \\
1449\end{array}$ & $\begin{array}{l}\text { this work } \\
\text { Hsu and DeMore } \\
\text { Hsu and DeMore }\end{array}$ \\
\hline $\begin{array}{l}\mathrm{CF}_{2} \mathrm{HOCF}_{2} \mathrm{H}(\mathrm{HFOC}-134) \\
\mathrm{CF}_{2} \mathrm{HCF}_{2} \mathrm{H}(\mathrm{HFC}-134)\end{array}$ & $\begin{array}{l}1.9 \mathrm{E}-12 \\
1.6 \mathrm{E}-12\end{array}$ & $\begin{array}{l}2006 \\
1680\end{array}$ & $\begin{array}{l}\text { this work } \\
\text { DeMores }\end{array}$ \\
\hline $\begin{array}{l}\mathrm{CF}_{3} \mathrm{OCF}_{2} \mathrm{H}(\mathrm{HFOC}-125) \\
\mathrm{CF}_{3} \mathrm{CF}_{2} \mathrm{H}(\mathrm{HFC}-125) \\
\mathrm{CF}_{3} \mathrm{H}(\mathrm{HFC}-23)\end{array}$ & $\begin{array}{l}4.7 E-13 \\
5.6 E-13 \\
6.4 E-13\end{array}$ & $\begin{array}{l}2095 \\
1700 \\
2354\end{array}$ & $\begin{array}{l}\text { this work } \\
\text { JPL Publication } 94-26 \\
\text { Hsu and DeMore }\end{array}$ \\
\hline
\end{tabular}

for the halogenated hydrocarbons. It is evident from the present work that the $\mathrm{CF}_{3} \mathrm{O}$ group behaves in much the same manner as an $\mathrm{F}$ atom. Replacement of an $\mathrm{H}$ atom in $\mathrm{CH}_{4}$ by either $\mathrm{F}$ or $\mathrm{CF}_{3} \mathrm{O}$ enhances the reactivity of the remaining $\mathrm{C}-\mathrm{H}$ bonds. Thus, $\mathrm{CH}_{3} \mathrm{~F}$ and $\mathrm{CF}_{3} \mathrm{OCH}_{3}$ both react on a per hydrogen basis faster than $\mathrm{CH}_{4}$. When two $\mathrm{F}$ atoms are already present on the carbon atom (in addition to $\mathrm{F}$ or $\mathrm{CF}_{3} \mathrm{O}$ ), as in $\mathrm{CF}_{3} \mathrm{OCF}_{2} \mathrm{H}$ or $\mathrm{CF}_{3} \mathrm{H}$, the enhancing effects of the three substituents are not only reduced but are in fact replaced by a net suppressing effect. The rate constants are much lower than that of $\mathrm{CF}_{2} \mathrm{H}_{2}$ on a per hydrogen basis. This behavior has not been observed for any other substituents, with the exception that it appears from the present work to occur for the somewhat similar $\mathrm{CHF}_{2} \mathrm{O}$ group. The latter follows from the fact that in $\mathrm{CHF}_{2} \mathrm{OCHF}_{2}, k / n(\mathrm{H})$ is also reduced below that of $\mathrm{CF}_{2} \mathrm{H}_{2}$ by the replacement of an $\mathrm{H}$ by $\mathrm{CHF}_{2} \mathrm{O}$.

The compound $\mathrm{CHClF}_{2}$ (HCFC-22) appears to be a borderline case, wherein the normal enhancing effect of $\mathrm{Cl}$ is essentially neutralized by the two $\mathrm{F}$ atoms. Hence, $\mathrm{CF}_{2} \mathrm{H}_{2}$ and $\mathrm{CHClF}_{2}$ have nearly equal values for $k / n(\mathrm{H})$, as seen in Figure 4 .

The presence of two $\mathrm{F}$ atoms not only offsets the enhancing effects of groups but also mitigates the suppressing effects which a very few single groups have. In the case of $\mathrm{CF}_{3}$, the presence of two $\mathrm{F}$ atoms on the carbon atom (as in $\mathrm{CF}_{3} \mathrm{CF}_{2} \mathrm{H}$ ) reduces the suppressive effect, with the result that the compound $\mathrm{CF}_{3} \mathrm{CF}_{2} \mathrm{H}$ has a $k / n(\mathrm{H})$ which is greater than that of $\mathrm{CH}_{3} \mathrm{CF}_{3}$, the compound to which it should be compared in this connection. It is therefore apparent that $\mathrm{CF}_{3} \mathrm{O}$ and $\mathrm{CF}_{3}$ behave quite differently, and in fact oppositely, in their roles as substituent groups. No simple analogies can be expected for the $\mathrm{OH}$ abstraction rate constants of compounds containing these groups.

From Table 5 we see, as suggested above, that the effects of the fluoro ether groups are due to changes in $E / R$ for the reactions, and not to differences in $A$ factors. The $A / n(\mathrm{H})$ values are similar for the three sets of reactions, and the large dissimilarities in the rate constants are due to differences in $E / R$. It may be noted that the Arrhenius parameters for the pairs $\mathrm{CH}_{3} \mathrm{~F}$ and $\mathrm{CF}_{3} \mathrm{OCH}_{3}$, as well as $\mathrm{CF}_{3} \mathrm{H}$ and $\mathrm{CF}_{3} \mathrm{OCF}_{2} \mathrm{H}$, are rather similar, showing again that in this regard the $\mathrm{CF}_{3} \mathrm{O}$ group behaves much like an $F$ atom.

Bond Energies. Figure 5 shows a correlation plot for $\log (k(298 \mathrm{~K}) / n(\mathrm{H}))$ vs the $\mathrm{C}-\mathrm{H}$ bond dissociation energy for several methane derivatives. The values for the $\mathrm{C}-\mathrm{H}$ bond energies in the fluoro ethers which fit this correlation are (in $\mathrm{kcal} / \mathrm{mol}): 102\left(\mathrm{CF}_{3} \mathrm{OCH}_{3}\right), 104\left(\mathrm{CHF}_{2} \mathrm{OCHF}_{2}\right)$, and 106 $\left(\mathrm{CF}_{3} \mathrm{OCF}_{2} \mathrm{H}\right)$. These values are shown on the plot. On the basis of the scatter in the correlation plot, there is an uncertainty of about $1 \mathrm{kcal} / \mathrm{mol}$ in the fit, aside from any uncertainty in the bond energies used to establish the correlation. A similar correlation (not shown here) using haloethanes gives the same result, as does a correlation of $\log (k / n)$ vs $E / R$ for both the methanes and ethanes.

Acknowledgment. We have benefited greatly from frequent discussions with members of the JPL Kinetics and Photochemistry group. We are especially grateful to Dr. Robert Hampson for many comments during the course of this work. The DuPont Co. generously provided the HFOC samples used in this work. This research was carried out by the Jet Propulsion Laboratory, California Institute of Technology, under contract with the National Aeronautics and Space Administration.

\section{References and Notes}

(1) Zhang. Z.: Saini. R. D.: Kurylo. M. J.: Huie. R. E. J. Phys. Chem. 1992. 96.9301

(2) Garland. N. L.: Medhurst. L. J.: Nelson. H. H. J. Geophys. Res. 1993. 98.23107.

(3) Orkin. V. L.: Khamaganov, V. G.: Guschin. A. G.: Huje. R. E.: Kurylo. M. J. In The 13th Intemational Sumposium on Gas Kinetics: The University College Dublin: Dublin, Ireland. 1994

(4) DeMore. W. B. Geophys. Res. Lett. 1992. 19. 1367

(5) DeMore, W. B. Geophvs. Res. Lett. 1993. 20. 1359.

(6) Huder. K.: DeMore. W. B. Geophys. Res. Lett. 1993. 20. 1575

(7) Hsu. K. J.: DeMore. W. B. Geophvs. Res. Lett. 1994. 21. 805.

(8) Hsu. K. J.: DeMore. W. B. J. Phys. Chem. 1995. 99. 1235.

(9) DeMore. W. B.: Golden, D. M.: Hampson. R. F.: Howard. C. J.: Kolb. C. E.: Kurylo. M. J.: Molina. M. J.: Ravishankara. A. R.: Sander, S. $P$. Chemical Kinetics and Photochemical Data for Use in Stratospheric Modeling. JPL Publication 94-26. Jet Propulsion Laboratory. California Institute of Technology, 1994.

JP9505643 